\title{
REVIEW
}

\section{Fishing for neuroendocrine tumors}

\author{
Germano Gaudenzi ${ }^{1}$, Silvia Carra2, Alessandra Dicitore ${ }^{3}$, Maria Celeste Cantone ${ }^{3}$, Luca Persani2,3 and \\ Giovanni Vitale1,3
}

1/stituto Auxologico Italiano, IRCCS, Laboratorio Sperimentale di Ricerche di Neuroendocrinologia Geriatrica ed Oncologica, Milan, Italy IIstituto Auxologico Italiano, IRCCS, Laboratorio Sperimentale di Ricerche Endocrino-Metaboliche, Milan, Italy

3Department of Clinical Sciences and Community Health (DISCCO), University of Milan, Milan, Italy

Correspondence should be addressed to G Vitale: giovanni.vitale@unimi.it

\begin{abstract}
Neuroendocrine tumors (NETs) are a class of rare and heterogeneous neoplasms that originate from the neuroendocrine system. In several cases, these neoplasms can release bioactive hormones leading to characteristic clinical syndromes and hormonal dysregulations with detrimental impact on the quality of life and survival of these patients. Only few animal models are currently available to investigate pathogenesis, progression and functional syndromes in NETs and to identify new therapeutic strategies. The tropical teleost zebrafish (Danio rerio) is a popular vertebrate model system that offers unique advantages for the study of several biological processes, ranging from embryonic development to human diseases such as cancer. In this review, we summarize recent advances on zebrafish models for NET preclinical research that take advantage of modern genetic and transplantable technologies. In the future, these tools may have a role in the treatment decision-making and tertiary prevention of NETs.
\end{abstract}

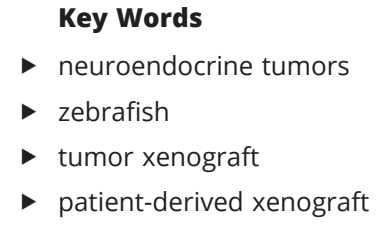

Endocrine-Related Cancer (2020) 27, R163-R176

\section{Introduction}

Neuroendocrine tumors (NETs) represent a broad class of neoplasms originating from neuroendocrine cells. NETs can cause a wide array of symptoms depending on the type of tumor, its location and the production of several factors. In functioning tumors, the release of several bioactive hormones can lead to characteristic clinical syndromes and hormonal dysregulations, with detrimental impact on the quality of life and survival of these patients. Non-functioning NETs are the majority of tumors. They do not release bioactive hormones and are often clinically silent for a long time. As a result, non-functioning NETs are diagnosed in the later stages after the occurrence of symptoms related to the mass effect of the tumor or metastases. (Rindi \& Wiedenmann 2011, De Angelis et al. 2018). Although surgery remains the cornerstone of treatment for localized tumors, most patients with NETs are diagnosed when they already have metastases, because these neoplasms are often indolent. In advanced disease, the efficacy of current medical strategies is limited by the high biological heterogeneity of these neoplasms in terms of clinical aggressiveness and response to the therapy (Uri \& Grozinsky-Glasberg 2018, Alexandraki et al. 2019).

In this context, new animal models that faithfully recapitulate clinical features and related complexity of NETs are needed for the development of innovative therapeutic strategies and to clarify the mechanisms involved in tumor progression. Although rodents represent the main animal model in cancer research, the use of this model in the field of NETs is very limited. In the last decade, the use of zebrafish (Danio rerio) in biomedical research is growing exponentially, with relevant applications in studying human diseases (Lohr \& Hammerschmidt 2011), such as cancer modeling (Astell \& Sieger 2019, 
Hason \& Bartunek 2019, Osmani \& Goetz 2019). In 2014, we have published an article providing a comprehensive overview of zebrafish in NET research, describing genetic models and our preliminary results of NET xenotransplantation in zebrafish embryos. In the present review, we provide an update on these models, underlying how the availability of multiple experimental strategies makes zebrafish extremely versatile in the NET research.

\section{Zebrafish model in cancer research}

The teleost zebrafish has emerged as a relevant in vivo model for research in genetic and embryology. The appeal for these animals lies in the high fecundity, the outer fertilization, the rapidity of embryonic and larval development and the optical transparency of zebrafish embryos. Moreover, compared to other vertebrate models, adult zebrafish are very easy to maintain under laboratory conditions because of their size and the possibility to keep them in relatively high density. More recently, the focus of zebrafish research has progressively shifted toward topics that are also relevant for human diseases, including tumors (Santoriello \& Zon 2012, Shive 2013, Vitale et al. 2014, Gaudenzi et al. 2017, Peverelli et al. 2017, Wurth et al. 2017, Cirello et al. 2018).

Although zebrafish can develop tumors in various organs with high degree of histological and molecular conservation compared with human malignances (Stern \& Zon 2003), their spontaneous incidence is very low. However, alternative experimental approaches have been recently developed in zebrafish to study both genetic basis of cancer as well as tumor progression.

To generate genetic models of cancer, several forward and reverse strategies have been used in zebrafish. Through large scale forward genetic screening it is possible to identify cancer susceptibility genes, responsible for a specific and well-characterized phenotype. After the induction of random modifications throughout the genome, by carcinogens, irradiation or viral/transposonbased vectors, progeny can be easily screened for cancer phenotypes, taking advantage of embryonic and larval transparency. Causative mutations can be identified through genetic mapping and sequencing analysis. The rapid development of zebrafish genomic resources has promoted the identification of complementary reverse genetic approaches to investigate genes and pathways of interest. Compared to forward strategies, reverse genetic approaches are based on gene manipulation and transgene introduction into zebrafish genome, such as human genes with cancer-associated mutations, with the aim of generating tumor-related phenotypes. A reverse genetic approach, commonly used to study cancer-related genes in zebrafish embryos and larvae, is based on their transient knockdown or overexpression (Finckbeiner et al. 2011, Kim et al. 2017, Grosse et al. 2019). The transient gene knockdown strategy relies on the injection of specific morpholinos (MOs), synthetic antisense oligonucleotides in which the replacement of RNA ribose rings by morpholine rings prevents nuclease digestion. MOs, typically injected into embryos at the 1-cell stage, exert their knocking down action by binding complementary target mRNAs, thus preventing their translation or splicing. The transient overexpression during early zebrafish development (up to 3 days) is achieved by introducing the mRNA encoding the protein of interest into the embryos during the first $2 \mathrm{~h}$ of development. Given that MOs and exogenous RNAs are efficacious only few days after the injection, these techniques are of short duration and not suitable for functional studies beyond the larval period (Nasevicius \& Ekker 2000, Bill et al. 2009). Nevertheless, MO technology is adequate to study several developmental and cellular processes and molecular pathways that are also related to cancer biology (Amatruda et al. 2002, Hason \& Bartunek 2019). For instance, it has been reported that aggressive tumor cells show aberrant activation of embryonic signaling, such as nodal and notch pathways, leading to a multipotent phenotype similar to embryonic stem cells (Strizzi et al. 2009). Also, Wnt signaling has been tightly associated with both development and cancer (Zhan et al. 2017). In this frame, the possibility to easily modulate the expression of novel Wnt signaling regulator during early zebrafish development by means of MO technology (Kim et al. 2017, Grosse et al. 2019) represents a unique opportunity to investigate aberrant molecular events involved in carcinogenesis.

Cancer modeling in zebrafish can also rely on numerous mutant and transgenic lines that allow study of cancer-related phenotypes in a broader temporary window (Shive 2013). Several strategies are currently available to create mutant lines in zebrafish. They are based on the possibility to generate double-strand breaks at specific sites in the zebrafish genome that can be imprecisely repaired by non-homologous end joining (NHEJ), a DNA repair pathway that frequently causes small insertions or deletions at the break site. One of these strategies is based on Zinc finger endonucleases, in which a DNA-binding zinc finger protein is fused to a nonspecific cleavage domain of the FokI endonuclease. Upon binding to a specific DNA 
sequence by the zinc-finger motifs, FokI endonuclease can induce double-strand breaks that can be imprecisely repaired by NHEJ (Santoriello \& Zon 2012, Shive 2013). Another strategy for genome engineering is based on TALENs, chimeric nucleases generated by a transcription activator-like effector DNA-binding domain, constructed to bind any desired DNA sequence fused to a DNA cleavage domain (Santoriello \& Zon 2012, Shive 2013). At the moment, the most used strategy for the genome editing is CRISPR-Cas9, an adaptive immune system used by bacteria and archaea against invading foreign nucleic acids derived from bacteriophages or exogenous plasmids. A chimeric single guide RNA is synthetized to interact with the complementary strand of the DNA target site, close to protospacer adjacent motif sequence, which is recognized and cleaved by Cas9 protein (Liu et al. 2017).

Another strategy to generate genetic models of cancer in zebrafish is based on transgenic animals in which tissuespecific promoters regulate the expression of murine or human oncogene, in both WT and mutated form (Santoriello \& Zon 2012). In order to improve degree and precision of temporal and spatial expression of exogenous genes, several technologies have been adopted, such as Tol2 transposon and the mifepristone-inducible LexPR, GAL4-UAS and Cre-LoxP systems (Santoriello \& Zon 2012). Moreover, it has been recently demonstrated that transgene electroporation can allow the spatio-temporal expression of specific oncogenes directly into adult somatic tissue (Callahan et al. 2018).

A limitation of both transient and stable genetic cancer models is related to the duplication that occurred in the stem lineage of teleost (Postlethwait et al. 2000). Considering that at least $20 \%$ of duplicated gene pairs may be retained from this event (Postlethwait et al. 2000), several human genes have more than one ortologue in zebrafish, leading to an extra work to investigate their specific functional roles and difficulties to reproduce the molecular conditions of human patients in zebrafish.

In addition to genetic basis of cancer, zebrafish offers the possibility to study several aspects of tumor progression (cell-stromal interactions, tumor-induced angiogenesis and metastasis formation) by performing xenotransplantation of human or mouse cancer cells in several sites of embryos, larvae, juvenile and adult fish. At present, embryo represents the most commonly used recipient for cancer xenograft assays in zebrafish. These studies can benefit from both intrinsic features of zebrafish model and the availability of transgenic lines that express fluorescent proteins in normal tissues, such as endothelium or immune system (Konantz et al. 2012,
Hason \& Bartunek 2019). Although murine models remain the gold standard for xenotransplantation studies, tumor implant in zebrafish, and in particular in its embryos, can overcome some relevant drawbacks reported in mice (Zhao et al. 2015). For instance, maintenance cost of a zebrafish facility is lower than in mice and its management is simpler. The response to tumor implantation in zebrafish embryos, in terms of proangiogenic effects of implanted cells or their metastatic behavior, can be readily observed in real time and only after $24 \mathrm{~h}$ post injection (hpi), a time window narrower than that required in mice, ranging from few weeks to months. Immunosuppression is not needed because zebrafish embryos do not have a fully developed immune system, thus no graft rejection occurs at this stage of development. Besides, zebrafish offers the possibility to study the effects of small tumor implants (100-1000 cells/embryo), compared to larger implants (about 1 million cells) required in mice. In addition to the implantation of immortalized cell lines, zebrafish has been used as recipient for the injection of primary cultures, derived from post-surgical tumor samples (Vitale et al. 2014, Gaudenzi et al. 2017, Peverelli et al. 2017, Wurth et al. 2017, Cirello et al. 2018). These patient-derived xenografts (PDXs), largely employed in murine models, preserve the histological organization, the genetic and epigenetic mutational profile and the gene expression pattern, as in the patient counterpart. Due to these peculiarities, PDXs are currently considered a powerful platform for the development of precision medicine (Byrne et al. 2017). Recently, an elegant study has demonstrated that PDXs of human colorectal cancer in zebrafish embryos respond to the available therapeutic options as in patients (Fior et al. 2017). Thus, PDXs in zebrafish embryos (zPDXs) may open new frontiers in the personalization of anticancer treatment. Indeed, tumor xenografts in zebrafish embryos represent an advantageous platform to perform drug screening of new anticancer molecules. Because of the permeability of zebrafish embryos to small molecules, these drugs can be added directly to the embryo water, whereas larger or not water-soluble molecules can be injected into the blood circulation (Konantz et al. 2012, Fior et al. 2017, Hason \& Bartunek 2019, Osmani \& Goetz 2019).

Despite the described advantages, tumor xenografts in zebrafish embryos have few potential limitations that need to be considered. For instance, zebrafish embryos are maintained at $28^{\circ} \mathrm{C}$ and this may not represent an optimal temperature for mammalian cell growth and metabolism. Species-specific microenvironmental differences may affect the behavior of grafted mammalian https://erc.bioscientifica.com

https://doi.org/10.1530/ERC-19-0437 (c) 2020 Society for Endocrinology Published by Bioscientifica Ltd. Printed in Great Britain 
tumor cells. The lack of some mammalian organs in fishes (such as mammary gland, prostate and lung) precludes the possibility to perform orthotopic transplantations as in mice. Although embryonic organs and systems are completely defined, their differentiation is incomplete in embryos. This aspect together with the physiological differences between fish and mammals may influence drug metabolism in zebrafish, which may be different from that in mammals (Gaudenzi et al. 2019). Advantages and limitations in performing tumor xenografts in zebrafish embryos are summarized in Table 1.

Tumor xenografts can be performed also in juvenile and adult zebrafish. The availability of casper mutant strain, lacking all melanocytes and iridophores, offers the unique possibility to visualize tumor engraftment proliferation and metastasis formation in a large time window, from 5 days to 4 weeks, in adult fish (White et al. 2008). Moreover, the impact of the tumor graft on the mature vasculature of juvenile and adult zebrafish may better recapitulate tumor angiogenesis in cancer patients than embryos (Stoletov \& Klemke 2008). Finally, in adult fish, pharmacological treatment and the drug delivery may be potentially similar to mouse models, in fact drug administration in embryo fish medium could not permit accurate drug dosing, optimized drug schedule and evaluation of pharmacodynamics over extended periods (Stoletov \& Klemke 2008, Osmani \& Goetz 2019).

The main limitation of tumor cell allografts and xenografts is that immune suppression is required to ensure the survival of implanted cells. To this purpose, chemical treatment with dexamethasone or sublethal doses of $\gamma$ irradiation, (Langenau et al. 2004, Traver et al. 2004) can lead to a temporary ablation of the immune system in juvenile and adult zebrafish. However, these methods are not suitable for durable engraftment and consequently long-term tumor growth and dissemination analysis (Smith et al. 2010).
Alternatively, genetically immunocompromised fish, lacking the adaptive immunity, are currently available as tumor cell recipient. The first immunodeficient zebrafish line with the lack of mature T-cells and a reduction of B-cell number has been generated by Tang et al. (2014). New zebrafish immunodeficient models with affected T-cells, B-cells and natural killer (NK) cells have been recently developed (Moore et al. 2016, Yan et al. 2019). It has been demonstrated that a wide variety of tumor cell lines and patient-derived tumor cells grafted in these recipients have similar growth kinetics and histopathologic features to those grown in immunodeficient NOD scid gamma (NSG) mice (Yan et al. 2019). Therefore, these promising results support the use of adult zebrafish xenografts in the future of cancer research as a reliable preclinical model, comparable to the implantation in mice (Hason \& Bartunek 2019, Yan et al. 2019).

To overcome transplant rejection in adult zebrafish without immune suppression, it is possible to perform allograft between clonal homozygous zebrafish. This procedure allows the transfer of tumor tissues from one donor fish to another syngeneic fish belonging to the same line (Mizgireuv \& Revskoy 2006, Mizgirev et al. 2018). In this way it is possible to study tumor progression and tumor microenvironment over time in fish with fully functional immune system, but only between clonal fish.

\section{The neuroendocrine system in zebrafish}

Several lines of evidence indicate the conservation of neuroendocrine system in vertebrate, from fish to mammals, in terms of both morphological structures and their functions. As in mammals, the neuroendocrine regulation in zebrafish is based on the interconnection between structures of the CNS, such as hypothalamus and pituitary gland, and several peripheral organs including

Table 1 Advantages and limitations of tumor xenografts in zebrafish embryos.

\footnotetext{
Advantages

High number of embryos can be implanted in the same experiment

Real-time and in vivo monitoring of proangiogenic potential and metastatic behavior of injected tumor cells

Possibility to perform xenograft with few tumor cells (100 cells/embryo)

Tumor-induced angiogenesis within few days from the xenograft (24-48 h post injection)

Lack of a fully mature immune system in embryos

Permeability to small molecules
}

\author{
Limitations \\ The lack of several tissues and organs present in mammals limits \\ the possibility of orthotopic implantation \\ Long-term analyses are not possible \\ Embryos, after tumor cell implants, have to be raised at a \\ compromise temperature between the optimal for embryos and \\ tumor cells
}

(c) 2020 Society for Endocrinology Published by Bioscientifica Ltd. Printed in Great Britain 
the digestive system, interrenal gland, thyroid, gonads, fat tissue, kidney, gills and so on. The conservation of the neuroendocrine system is not only at anatomical level (Fig. 1). Indeed, neuropeptides, pituitary hormones and molecular signals from peripheral organs that support the activity of main neuroendocrine axes in zebrafish are very similar to those of mammals and are crucial for maintaining physiological homeostasis. For instance, the organization of the hypothalamic neuroendocrine system of zebrafish is made of nuclei that project into or toward the pituitary as in higher vertebrates (Lohr \& Hammerschmidt 2011). Orthologs for six hypothalamic neurohormones that regulate the activity of anterior pituitary gland, such as thyrotropin-releasing hormone, corticotropin-releasing hormone, growth hormonereleasing hormone (GHRH), somatostatin, gonadotropinreleasing hormone and dopamine, have been isolated in zebrafish. Moreover, zebrafish hypothalamus expresses the orthologs of mammalian oxytocin and vasopressin, called isotocin (Unger \& Glasgow 2003) and vasotocin (Eaton et al. 2008), respectively, that are released into the bloodstream via the posterior pituitary. Like its mammalian counterpart, the zebrafish pituitary consists of two different parts, which differ in developmental origin and physiology. The posterior pituitary that derives from a ventral extension of the hypothalamus represents the neural compartment of the gland (Pogoda \& Hammerschmidt 2007, Toro et al. 2009). The anterior pituitary, derived from placodal ectoderm, contains distinct endocrine cell lineages which specifically secrete the thyroid-stimulating hormone, the adrenocorticotropic hormone (ACTH), the $\alpha$-melanocytestimulating hormone, the growth hormone $(\mathrm{GH})$, the follicle-stimulating hormone, the luteinizing hormone, prolactin (PRL) and somatolactin. This last is a member of the GH/PRL family, unique to bony fish, implicated in several physiological processes (energy homeostasis, stress response, reproduction, fat or ion metabolism, acidosis, pigmentation, etc.) (Gonzalez-Nunez et al. 2003, Herzog et al. 2003, Liu et al. 2003, Zhu et al. 2004, So et al. 2005, Lopez et al. 2006, Chen \& Chiou 2010, Lohr \& Hammerschmidt 2011).

Classical feedback mechanisms, involving signals from peripheral organs, contribute to the regulation of hypothalamic and anterior pituitary hormone secretion. A typical example about the integration of

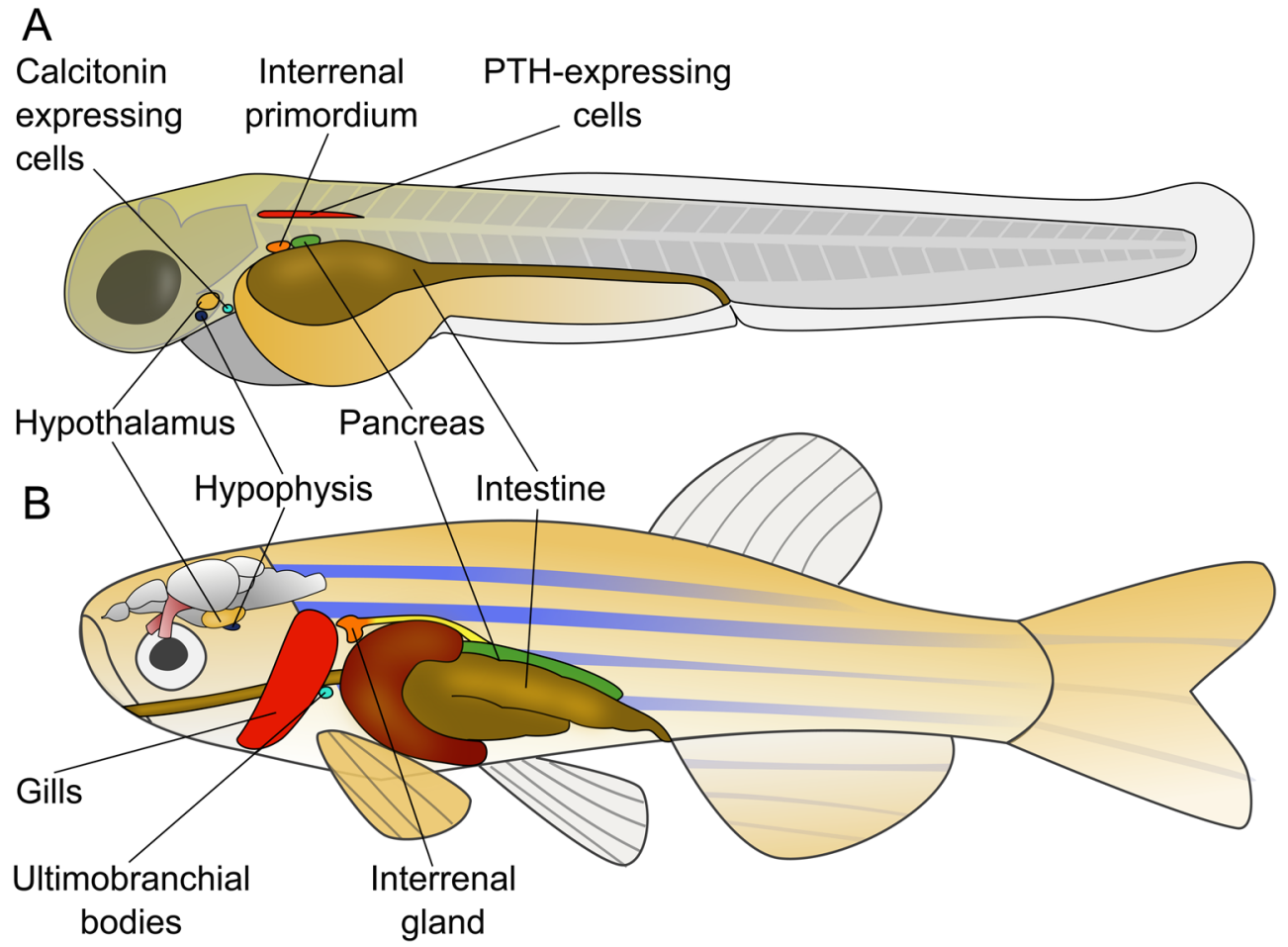

Figure 1

Schematic drawing depicting major zebrafish neuroendocrine structures in a larva of about 3 days post fertilization (A) and in an adult fish (B). Black lines indicate hypothalamus, hypophysis, ultimobranchial bodies and their calcitonin-expressing precursor cells, interrenal gland and its primordium, gills and PTH-expressing cells during larval development and intestine, in which neuroendocrine enterochromaffin cells are dispersed. Pancreas, probably the best characterized endocrine organ, is also indicated. 
central and peripheral signals is represented by the hypothalamic-pituitary-interrenal axis that, homologous to the human hypothalamic-pituitary-adrenal axis, regulates the corticosteroid stress response in zebrafish. The hypothalamic CRF stimulates the release of ACTH from the pituitary, which stimulates the secretion of cortisol by the interrenal gland, homologous to the adrenal cortex in mammals. Interestingly, cortisol is the main stress hormone as in humans, while mice and rats utilize corticosterone (Nesan \& Vijayan 2013). A negative feedback system acts on the hypothalamus to ensure homeostatic regulation. The stress response in zebrafish is mediated not only by glucocorticoids but also by catecholamine, which are secreted by chromaffin tissue, the homologue of mammalian adrenal medulla (Eto et al. 2014).

Moreover, other typical structures of zebrafish neuroendocrine system are conserved compared to human. For instance, zebrafish has calcitonin secreting cells that are homologues to mammalian C-cells. Unlike humans, in which C-cells are dispersed throughout the thyroid parenchyma, these zebrafish cells arise from the ultimobranchial bodies, a bilateral structure close to the heart atrium, which does not fuse with the thyroid (Bourque \& Houvras 2011). Calcitonin, secreted by these cells, exerts a hypocalcemic fuction as in the mammalian counterpart (Alt et al. 2006).

Gill tissue of zebrafish may represent an evolutionary ancestor of the parathyroid gland in higher vertebrates (Okabe \& Graham 2004). Gill cells produce calcium sensing receptor and parathyroid hormone (PTH), whose hypercalcemic function is conserved during the evolution (Lin et al. 2014).

Interestingly, zebrafish neuroendocrine system is made not only of anatomically recognizable structures (e.g. pituitary, interrenal gland, etc.), but also of cells that are dispersed in several tissues, similar to the human diffuse neuroendocrine system. For instance, the population of zebrafish enterochromaffin cells in the intestinal tract, as the human counterpart, derives from the neural crest cells and controls intestinal motility by secreting serotonin (Njagi et al. 2010).

Moreover, zebrafish has been broadly used to study other endocrine organs. Among these, the pancreas is the most intensively studied. Developmental pathways building and maintaining the cell types of the pancreas are generally conserved in vertebrates. The expression of typical pancreatic hormones, such as insulin, glucagon, somatostatin and ghrelin, has already been detected by $15 \mathrm{~h}$ post-fertilization (hpf) in pancreatic progenitor cells of zebrafish embryos (Tiso et al. 2009). Zebrafish adult pancreas shares not only the general anatomical structure with the mammalian pancreas, but also its physiological role in the regulation of glucose metabolism through the secretion of insulin, somatostatin and glucagon (Krishnan $\&$ Rohner 2019).

\section{Zebrafish and NETs}

Since our previous review (Vitale et al. 2014), the number of zebrafish studies on NETs has slightly increased. Below, we summarize recent updates regarding currently available genetic and transplantable zebrafish models for NETs.

\section{Genetic models}

Several genetic models, developing NETs or relatedsyndromes during developmental stages, or in adult zebrafish have been established taking advantage of technologies for the generation of mutant and transgenic animals, as well as for transient modulation of gene expression during embryonic development (Table 2). These models represent a powerful platform to understand carcinogenesis of NETs, as well as to identify new therapeutic strategies.

Between zebrafish mutant lines, there are many noteworthy examples for the study of molecular conditions predisposing to human NETs, even if these zebrafish models do not clearly develop these neoplasms. For instance, inactivating mutations in zebrafish Von Hippel-Lindau $(v h l)$ gene led to several key conditions of the human VHL disease, a continuum of multiple endocrine neoplasia (MEN), which is characterized by a constellation of cysts and extensively vascularized tumors, including several NETs such as pheochromocytomas and pancreatic NETs (Richard et al. 2013). Although these mutants do not develop NETs, they are characterized by the activation of Hif signaling pathway, severe pathological neovascularization, macular edema, pronephric abnormalities and polycythemia as in human (van Rooijen et al. 2011, 2018, 2010). In this frame, vhl mutants have been recently used to test the efficacy of several compounds in rescuing VHL phenotype. For instance, it has been demonstrated that sunitinib malate, a multi-tyrosine kinase inhibitor, was able to reverse the ocular, behavioral and morphological phenotypes observed in homozygous vhl zebrafish mutants (Ward et al. 2019). Therefore, these mutants represent a 
Table 2 Currently available zebrafish genetic models for preclinical research in NETs.

\begin{tabular}{|c|c|}
\hline & Model \\
\hline \multirow[t]{5}{*}{ Mutant lines } & vh/ mutants \\
\hline & nf1 mutants \\
\hline & tsc2 mutants \\
\hline & usp39 mutants \\
\hline & ret mutants \\
\hline \multirow[t]{4}{*}{$\begin{array}{l}\text { Transgenic } \\
\text { lines }\end{array}$} & $\begin{array}{l}\text { Transient overexpression of human MYCN } \\
\text { under myod promoter }\end{array}$ \\
\hline & $\begin{array}{l}\text { Transient overexpression of human } M Y C N \\
\text { and } A L K \text { in peripheral sympathetic nervous } \\
\text { system }\end{array}$ \\
\hline & $\begin{array}{l}\text { Stable overexpression of pttg under pomc } \\
\text { promoter }\end{array}$ \\
\hline & $\begin{array}{l}\text { Stable and ubiquitous overexpression of } \\
\text { tilapia GH }\end{array}$ \\
\hline \multirow{2}{*}{$\begin{array}{l}\text { Reverse } \\
\text { genetics }\end{array}$} & aip morpholino-mediated knockdown \\
\hline & ret morpholino-mediated knockdown \\
\hline
\end{tabular}

\begin{tabular}{|c|c|}
\hline Phenotypes & References \\
\hline $\begin{array}{l}\text { Partial recapitulation of human VHL } \\
\text { phenotype }\end{array}$ & $\begin{array}{l}\text { van Rooijen et al. 2010, 2011, } \\
\text { 2018, Ward et al. } 2019\end{array}$ \\
\hline $\begin{array}{l}\text { Partial recapitulation to human } \\
\text { neurofibromatosis type } 1\end{array}$ & Shin et al. 2012, Ki et al. 2017 \\
\hline $\begin{array}{l}\text { Partial recapitulation of human } \\
\text { tuberous sclerosis complex } \\
\text { phenotype }\end{array}$ & $\begin{array}{l}\text { Kim et al. 2011, 2013, } \\
\text { Scheldeman et al. 2017, } \\
\text { Serra et al. } 2019\end{array}$ \\
\hline $\begin{array}{l}\text { Microcephaly and pituitary } \\
\text { hyperplasia }\end{array}$ & Rios et al. 2011 \\
\hline $\begin{array}{l}\text { Partial recapitulation of } \\
\text { Hirschsprung's disease phenotype }\end{array}$ & Heanue et al. 2016 \\
\hline $\begin{array}{l}\text { Abdominal tumors resembling } \\
\text { human pancreatic neuroendocrine } \\
\text { carcinoma }\end{array}$ & Yang et al. 2004 \\
\hline $\begin{array}{l}\text { Tumors resembling human } \\
\text { neuroblastoma }\end{array}$ & Zhu et al. 2012 \\
\hline $\begin{array}{l}\text { Recapitulation of human Cushing's } \\
\text { Disease phenotype }\end{array}$ & Liu et al. 2011 \\
\hline $\begin{array}{l}\text { Recapitulation of acromegaly } \\
\text { phenotype }\end{array}$ & Elbialy et al. 2018 \\
\hline Hyperplasia of the pituitary gland & $\begin{array}{l}\text { Igreja et al. 2010, Stojanovic } \\
\text { et al. } 2016\end{array}$ \\
\hline $\begin{array}{l}\text { Partial recapitulation of } \\
\text { Hirschsprung's disease phenotype }\end{array}$ & Burzynski et al. 2009 \\
\hline
\end{tabular}

promising platform not only to study molecular basis of VHL disease, but also to identify innovative treatments for this complex pathology.

Another interesting zebrafish mutant model is characterized by Nf1 deficiency (Shin et al. 2012), a genetic condition that in humans causes neurofibromatosis type 1 . Nf1 zebrafish mutants have similar phenotypes to those reported in humans, such as abnormal patterning of the melanophores and the predisposition to cancer development, in particular tumors of the CNS or gastrointestinal tract and malignant peripheral nerve sheath tumors (MPNSTs) (Shin et al. 2012). Although it has not been reported if these tumors have a neuroendocrine phenotype, zebrafish nf1 mutants may represent a valid platform to study molecular events underlying tumor susceptibility in patients with neurofibromatosis type 1. Indeed, it has been recently reported that the overexpression of the receptor tyrosine kinase plateletderived growth factor receptor- $\alpha$ (Pdgfra) in $n f 1$ mutant background was more active in accelerating MPNST initiation (Ki et al. 2017). The kinase inhibitor sunitinib, alone and in combination with the MEK inhibitor trametinib, was able to delay MPNST progression in transgenic fish overexpressing Pdgfra (Ki et al. 2017). Interestingly, $n f 1$ zebrafish mutants are also a promising platform to perform drug screening. In particular, $n f 1$ mutants have been used to test the pharmacological inhibition of downstream targets of RAS (PI3K and MAPK) (Ki et al. 2017), given that neurofibromin acts as a suppressor of the RAS activity.

Another genetic model with potential applications for the identification of new drugs for NET treatment is the mutant zebrafish line that harbors a nonsense mutation in tuberous sclerosis complex 2 (tsc2) gene. Mutations in the human homologous lead to an autosomal dominant disease, characterized by the development of multiple hamartomas and occasionally NETs. Although the occurrence of NETs has not been reported in zebrafish tsc2 mutants, they exhibited, as TSC patients, hamartoma formation in the brain and activation of the TOR pathway (Kim et al. 2011). This pathway has been recently indicated as pivotal for NET tumorigenesis and progression (Manfredi et al. 2015). Interestingly, few studies showed the ability of rapamycin, an mTOR inhibitor, in reducing tumor proliferation and vascularization in tsc2 mutants (Kim et al. 2013, Scheldeman et al. 2017). Therefore, zebrafish tsc2 mutant larvae appear to be a potential platform for testing TOR inhibitors (Serra et al. 2019) and to identify new therapeutic targets in TSC patients (Scheldeman et al. 2017).

Since our previous review, no advances have been reported on the mutant line harboring a mutation in (c) 2020 Society for Endocrinology Published by Bioscientifica Ltd. Printed in Great Britain 
ubiquitin-specific peptidase 39 (Usp39), a zebrafish model with potential applications in studying a new mechanism for pituitary tumorigenesis (Rios et al. 2011).

The generation of transgenic lines is another approach to model NETs in zebrafish. Tumors resembling human pancreatic neuroendocrine carcinoma and human neuroblastoma have been identified in transgenic lines in which human MYCN was expressed under zebrafish myoD promoter (Yang et al. 2004) and in which human MYCN and activated anaplastic lymphoma kinase (ALK) genes were simultaneously overexpressed in peripheral sympathetic nervous system, respectively (Zhu et al. 2012). However, no updates have been recently reported on these models.

Due to the high conservation of main neuroendocrine hormones in vertebrates, transgenesis technology has been used in zebrafish to mimic several conditions associated to functioning NETs, due to excessive release of specific hormones. For instance, the transgenic line that expressed pituitary tumor transforming gene (pttg) under the control of proopiomelanocortin (pomc) gene in adenohypophyseal cells, showing ACTH-secreting pituitary tumors within the first days of embryonic development and in adult animals, has been proposed as a model for human Cushing Disease, a neuroendocrine disorder due to an uncontrolled ACTH hypersecretion by several NETs (Liu et al. 2011). More recently, Elbialy and collaborators established a stable acromegaly transgenic model that ubiquitously and constantly overexpresses GH of tilapia fish (Oreochromis niloticus) (Elbialy et al. 2018). Acromegaly is a hormonal disorder predominantly caused by a GH-secreting pituitary adenoma and more rarely due to NETs secreting GH or GHRH. Acromegaly patients show acral and facial overgrowth, soft-tissue hypertrophy, cardiovascular diseases, metabolic disturbances, osteoarthritis, an increased incidence of tumors, impaired quality of life and increased mortality (Chanson \& Salenave 2008, Fuentes-Fayos et al. 2019). Surprisingly, the model of Elbialy recapitulated several aspects of acromegalic patients, such as the acceleration of the growth and a significant increase of insulin-like growth factor I (IGF-I), known to mediate most biological actions of GH. Interestingly, the elevation of the GH/IGF-1 axis in this zebrafish acromegaly model was associated with a significant down-regulation of DNA repair pathways and a robust increase in the number of DNA-damaged cells. These findings provide additional support to explain the increased cancer susceptibility in acromegaly (Elbialy et al. 2018). Moreover, this transgenic model may be a reliable platform to clarify mechanisms by which GH excess induces these complications in acromegalic patients.

Recent studies have also exploited MO technology to knockdown NET-related genes, as in the case of aryl hydrocarbon receptor interacting protein (AIP) gene. The human ortologue is mutated in the germline of about $15-40 \%$ of familial pituitary adenomas (Igreja et al. 2010), and patients with mutations are predisposed to develop large, invasive, GH- or PRL-secreting pituitary tumors, occurring at a younger age and poorly responsive to treatment (Stojanovic et al. 2016). The aip knockdown in zebrafish embryos resulted in brain, pericardium and swim bladder anomalies and general developmental delay, suggesting a developmental role. Moreover, morpholino-injected embryos exhibited larger surface of PRL immunostaining in the pituitary compared to controls, suggesting an increase in proliferative activity (hyperplasia or tumour) at pituitary level (Stojanovic et al. 2016).

Another peculiar NET-related gene is the RET protooncogene, whose germline mutations are causative of MEN2, a hereditary disorder characterized by medullary thyroid cancer and other NETs (Vitale et al. 2001). The sequence of zebrafish ret has a high identity with that of its human orthologue. It has been demonstrated that its MO-mediated knockdown during embryonic development resulted in a complete loss of the zebrafish enteric nervous system (Burzynski et al. 2009), as in Hirschsprung's disease, which is associated with human RET mutations. A more recent zebrafish model of Hirschsprung's disease, characterized by a point mutation in ret, showed that intestinal motility is severely compromised in ret homozygous mutants and partially impaired in heterozygous larvae (Heanue et al. 2016). Therefore, ret mutants, harboring mutations similar to those found in patients with MEN2, could represent a promising platform to study the molecular basis of this disease and to perform drug screening.

\section{NET xenografts in zebrafish embryos}

We have described the development of a tumor xenograft model in zebrafish embryos to study NETs, focusing on tumor-induced angiogenesis and invasive behavior of implanted cells (Table 3). The procedure was set up by implanting several immortalized human NET cell lines in the subperidermal cavity of $T g(f l i 1 a: E G F P)^{y^{1}}$ zebrafish embryos, which express EGFP in the entire vascular tree under the control of the endothelial fli1a promoter (c) 2020 Society for Endocrinology Published by Bioscientifica Ltd. Printed in Great Britain 
Table 3 Zebrafish transplantable models for preclinical research in NETs.

\begin{tabular}{|c|c|c|c|c|}
\hline NET implanted cells & Stage & Site of implantation & Applications & References \\
\hline Immortalized cell lines & $48 \mathrm{hpf}$ & $\begin{array}{l}\text { Subperidermal } \\
\text { cavity }\end{array}$ & $\begin{array}{l}\text { Evaluation of proangiogenic and metastatic } \\
\text { behavior, analysis of tumor microenvironment } \\
\text { contribute for tumor progression, drug } \\
\text { screening of anticancer molecules }\end{array}$ & (Vitale et al. 2014, 2017) \\
\hline $\begin{array}{l}\text { Patient-derived tumor } \\
\text { cells }\end{array}$ & $48 \mathrm{hpf}$ & $\begin{array}{l}\text { Subperidermal } \\
\text { cavity }\end{array}$ & $\begin{array}{l}\text { Evaluation of individual proangiogenic and } \\
\text { metastatic behavior, analysis of tumor } \\
\text { microenvironment contribution for tumor } \\
\text { progression, development of precision } \\
\text { medicine }\end{array}$ & $\begin{array}{l}\text { (Gaudenzi et al. 2017, } \\
\text { Peverelli et al. 2017, } \\
\text { Wurth et al. 2017) }\end{array}$ \\
\hline
\end{tabular}

hpf: hours post fertilization.

(Lawson \& Weinstein 2002, Vitale et al. 2014, 2017). NET grafted cells quickly led to the formation of endothelial structures, sprouting from physiological vessels of the subintestinal vein (SIV) plexus and the common cardinal vein (CCV) within $24 \mathrm{hpi}$. In the next $48 \mathrm{~h}$, these endothelial sprouts were progressively converted in vessels with heterogeneous diameters that could reach and penetrate the implanted tumor mass (Vitale et al. 2014). Tumor-induced angiogenesis is easily and accurately quantified through computerized image analysis. Taking also into consideration the permeability of embryo to small molecules dissolved in the fish water, zebrafish/NET xenograft represents an attractive, fast and technically simple platform to perform drug screening. Moreover, larger or not water-soluble molecules can be injected into the blood stream to ensure drug uptake (Gaudenzi et al. 2019). Due to the low proliferation rate of some NETs, the possibility to observe tumor progression in implanted zebrafish embryos in a small temporary window results particularly suitable to test the anti-angiogenic and the anti-metastatic potential of selected drugs, while it may limit the analysis of their anti-proliferative effects.

More recently, we have set up a procedure based on the injection of patient-derived NET tumor cells in zebrafish embryos (Fig. 2 and Table 3) (Gaudenzi et al. 2017). The appeal of this model is supported by the growing number of experimental evidences suggesting the use of zPDX in oncological research, substantially for their ability to better mimic the heterogeneity and the behavior of primary tumors compared to immortalized cell lines. In our procedure, NET primary cultures generated from postsurgical samples were stained with a fluorescent dye and implanted into the subperidermal cavity of $T g(f l i 1 a: E G F P) y 1$ zebrafish embryos. We have demonstrated that NET zPDXs have a robust proangiogenic potential and a strong invasive behavior. After only $24 \mathrm{hpi}$, NET cells migrated far from the injection site and invaded different parts of the embryo, in particular the area of the posterior caudal vein plexus (Fig. 2) (Gaudenzi et al. 2017, Peverelli et al. 2017, Wurth et al. 2017). Interestingly, injected NET cells preserved nuclear morphology and the expression of specific markers (Gaudenzi et al. 2017, Peverelli et al. 2017, Wurth et al. 2017). Due to the possibility to study the effects of small tumor implants (100-1000 cells/ embryo), zPDXs resulted particularly suitable for NETs, where the post-surgical availability of tumor cells is often limited (Gaudenzi et al. 2017). Moreover, the success of NET transplantation in zebrafish embryos resulted to be extraordinarily higher compared to that reported for PDX murine model (Morton \& Houghton 2007). All these results, together with recent evidences about the high potential of zPDX platform in predicting the clinical response to anticancer drugs in colorectal cancer (Fior et al. 2017), open a promising scenario for the development of precision medicine applications (Gaudenzi et al. 2019). In particular, zPDXs of NETs may be used in co-clinical trials that, up to now, have been developed only in mice. Similar to murine model, patient-derived tumor cells, isolated from a patient enrolled in a clinical trial, may be implanted into zebrafish embryos that are subsequently treated with the same drugs of the patient to emulate clinical response (Byrne et al. 2017, Koga \& Ochiai 2019). This approach, analyzing and integrating preclinical and clinical data in a real-time manner, could offer the possibility to identify the most appropriate and personalized therapy in patients with NETs, as well as to prevent drug resistance (Table 3).

Moreover, this zebrafish/NET xenograft platform may offer unique opportunities to study the contribution of tumor microenvironment (TME) for tumor progression in NETs. TME is characterized by a complex composition of different cell types including cancer cells, endothelial cells, immune cells and fibroblasts and different molecular players, such as pro-inflammatory and oncogenic mediators. TME is created and shaped by the tumor, which orchestrates molecular and cellular events with the aim to enhance the survival of tumor cells (Wang et al. 2017). 

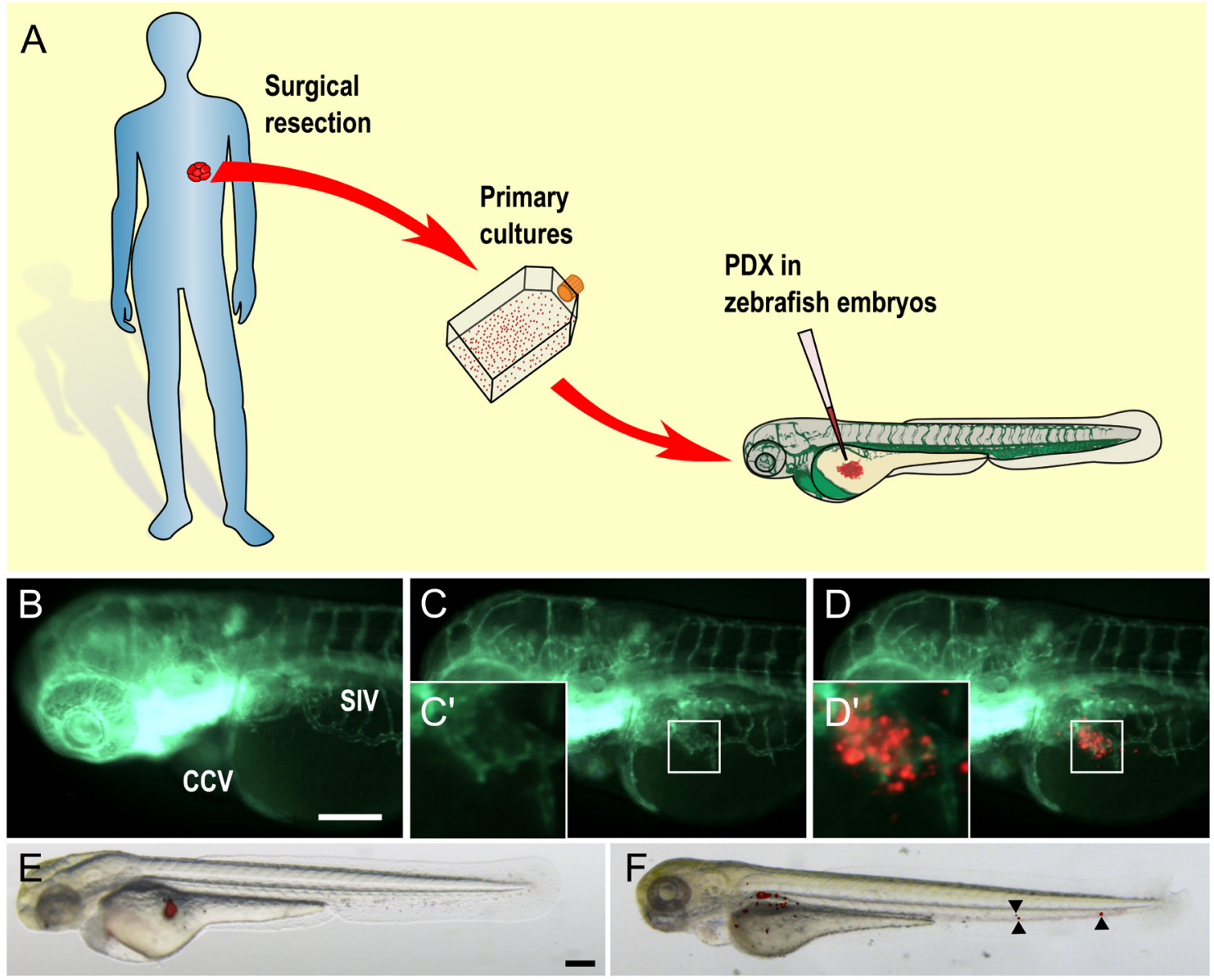

\section{Figure 2}

NET-PDX in zebrafish embryos. After the surgical resection, a portion of the fresh tumor is used to establish a NET primary culture. Red stained primary cell suspension is subsequently implanted in $48 \mathrm{hpf} \operatorname{Tg}(f l i 1 a: E G F P) y{ }^{1}$ zebrafish embryos (A). After the implantation, the pro-angiogenic (B, C and D) and invasive ( $E$ and F) potential of patient-derived grafted cells is followed in vivo. In this panel, representative epifluorescence and bright-field images, obtained after the implantation of a lung NET, are reported (B, C, D, E and F). Compared to PBS-injected control embryo (B), in which SIV (subintestinal vein) plexus is correctly formed, patient-derived NET xenografted embryo (C-D') showed the formation of endothelial structures (green), sprouting from the SIV, which reached the implanted tumor mass (red). In $C_{\text {and }} \mathrm{C}^{\prime}$, the red channel was omitted to highlight the newly formed endothelial structures; $\mathrm{C}^{\prime}$ and $\mathrm{D}^{\prime}$ are digital magnification of the graft region (white box). Overlay of representative fluorescent and bright-field images of grafted embryos at 0 ( $E$ ) and $24 \mathrm{hpi}$ (F) showed the spread of NET cells throughout the embryo body. Black arrowheads indicate migrating cells in the area of the posterior caudal vein plexus (F). All images are oriented so that rostral is to the left and dorsal is at the top. Scale bars: $100 \mu \mathrm{m}$ (B, C, D, E and F).

In this context, zebrafish xenograft is an ideal tool for the observation and analysis of tumor cell cross-talk with key players of TME, with the possibility to recapitulate in vivo and in real time its biological heterogeneity. In addition to evaluating tumor-induced angiogenesis, zebrafish have become a powerful model organism to study the innate immune system, mainly because zebrafish larvae have a similar repertoire of innate immune cell lineages to mammals, including neutrophils and macrophages (de Jong \& Zon 2005, Keightley et al. 2014). In particular, well-characterized reporter lines for imaging and distinguishing different leukocyte behaviors in vivo have been generated. These transgenic strains, paired with xenotransplantation of NET cells, may represent a novel tool to analyze the contribution of innate immune cells to the tumor progression in a living selective microenvironment, with significant translational and clinical implications. Different transgenic lines are available, such as $\operatorname{Tg}(m p x: E G F P)$, which expresses GFP in neutrophils (Renshaw et al. 2006); $\operatorname{Tg}(\operatorname{lys} C: G F P)$ or $T g(l y s C: d s R E D)$, whose labeled cells have hallmark traits of myelomonocytic cells, marking a subset of macrophages and likely also neutrophils (Hall et al. 2007); Tg(mpeg1:mCherry)gl23 and Tg(mpeg1:EGFP)gl22, which express red or green fluorescent proteins in monocytes/ macrophages (Ellett et al. 2011). Recently, the fish Tg(mpeg1:mCherryF/tnfa:eGFP-F) line, obtained by mating Tg(mpeg1:mCherry) fish with a transgenic line whose (c) 2020 Society for Endocrinology Published by Bioscientifica Ltd. Printed in Great Britain 
macrophages express tnfa (tumor necrosis factor alpha), characteristic of classically activated macrophages (M1), allows to show the dynamic macrophage activation in realtime and in vivo, including recruitment and phenotypic change after an injury or infection (Nguyen-Chi et al. 2015). The use of this transgenic line has emphasized the similarities between zebrafish and human macrophages in terms of diversity and plasticity of macrophage subsets.

Another attractive opportunity will be to create a 'humanized' zebrafish, adopting this fish as an ideal recipient for human neoplastic cells and other components of human TME, trying to reconstitute an interactive microenvironment that recapitulates a clinical situation. This procedure could provide a better understanding of the contribution to tumor progression of each cell type within TME.

It has been recently reported that human macrophages injected into blood circulation and hindbrain parenchyma of living zebrafish embryos can survive and express specific markers, such as TNF- $\alpha$, CD163 and VEGF, which in part identified M1 and M2 macrophage phenotypes. Moreover, tumor associated macrophages, isolated from different murine and human tumors and co-engrafted with tumor cells in zebrafish embryos, significantly potentiated the capacity of tumor invasiveness and metastasis, in particular M2 respect to M1 (Wang et al. 2015, Paul et al. 2019).

Finally, zebrafish xenotransplantation model may offer a real-time visualization of the impact of specific pharmacological treatments on TME, with relevant perspectives in the therapy of NETs.

\section{Conclusion and future perspectives}

The teleost zebrafish is an experimental model with wellrecognized advantages for the study of human tumors, including the heterogenous class of NETs. Although only few zebrafish models developing NETs have been produced until now, the advances in genome sequencing, the molecular conservation of NET-related genes in vertebrates and the availability of techniques to manipulate gene function offer unique opportunities to generate other relevant models in the future. For instance, the conservation of MEN1 gene between zebrafish and human may support the identification of zebrafish models to study human multiple endocrine neoplasia type 1 in the future.

The proved conservation of the neuroendocrine system from zebrafish to humans offers the possibility to study in zebrafish the effects of specific hormone dysregulations, described in human functioning NETs, and provides the development of reliable platforms for drug discovery. A possible experimental approach that may help the study of functioning syndrome could take advantage of transgenic lines that express reporter genes, encoding fluorescent proteins (EGFP, RFP, etc), in hormone producing cells. So far, this approach has been used in endocrine studies, in particular related to pancreatic cells, but could be also adopted for other neuroendocrine cell populations. For instance, Hesselson and collaborators used a transgenic approach to label two distinct populations of $\beta$-cells within the developing zebrafish pancreas that originate in distinct pancreatic buds. This transgenic line appeared to be a potential platform to perform drug screening to identify compounds able to regulate $\beta$-cell proliferation and function, with potential applications in pathological states that result from their excessive proliferation (e.g. insulinoma) or insufficient $\beta$-cell mass (e.g. diabetes mellitus) (Hesselson et al. 2009).

New advances in NET research may derived also result from the use of transplantable models, as innovative and promising platforms to investigate molecular events involved in tumor progression, and to perform screening of new anticancer compounds. The reported advantages of NET PDXs in zebrafish embryos, compared to mice, may support the development of precision medicine applications, aimed at predicting the most appropriate and personalized treatment. This approach may represent a breakthrough in the field of NETs, where the clinical management is extremely complex due to the high heterogeneity of these neoplasms in terms of clinical aggressiveness and response to the therapy.

\section{Declaration of interest}

The authors declare that there is no conflict of interest that could be perceived as prejudicing the impartiality of this review.

\section{Funding}

This work was supported by a grant from the Italian Ministry of Education, University and Research MIUR (PRIN 2017Z3N3YC), and a grant from the Neuroendocrine Tumor Research Foundation (Pilot Study 2019).

\section{References}

Alexandraki KI, Tsoli M, Kyriakopoulos G, Angelousi A, Nikolopoulos G, Kolomodi D \& Kaltsas GA 2019 Current concepts in the diagnosis and management of neuroendocrine neoplasms of unknown primary origin. Minerva Endocrinologica 44 378-386. (https://doi. org/10.23736/S0391-1977.19.03012-8) (c) 2020 Society for Endocrinology Published by Bioscientifica Ltd. Printed in Great Britain 
Alt B, Reibe S, Feitosa NM, Elsalini OA, Wendl T \& Rohr KB 2006 Analysis of origin and growth of the thyroid gland in zebrafish. Developmental Dynamics 235 1872-1883. (https://doi.org/10.1002/dvdy.20831)

Amatruda JF, Shepard JL, Stern HM \& Zon LI 2002 Zebrafish as a cancer model system. Cancer Cell 1 229-231. (https://doi.org/10.1016/ s1535-6108(02)00052-1)

Astell KR \& Sieger D 2019 Zebrafish in vivo models of cancer and metastasis. Cold Spring Harbor Perspectives in Medicine [epub]. (https:// doi.org/10.1101/cshperspect.a037077)

Bill BR, Petzold AM, Clark KJ, Schimmenti LA \& Ekker SC 2009 A primer for morpholino use in zebrafish. Zebrafish 6 69-77. (https://doi. org/10.1089/zeb.2008.0555)

Bourque C \& Houvras Y 2011 Hooked on zebrafish: insights into development and cancer of endocrine tissues. Endocrine-Related Cancer 18 R149-R164. (https://doi.org/10.1530/ERC-11-0099)

Burzynski G, Shepherd IT \& Enomoto H 2009 Genetic model system studies of the development of the enteric nervous system, gut motility and Hirschsprung's disease. Neurogastroenterology and Motility 21 113-127. (https://doi.org/10.1111/j.1365-2982.2008.01256.x)

Byrne AT, Alferez DG, Amant F, Annibali D, Arribas J, Biankin AV, Bruna A, Budinska E, Caldas C, Chang DK, et al. 2017 Interrogating open issues in cancer precision medicine with patient-derived xenografts. Nature Reviews: Cancer 17 254-268. (https://doi. org/10.1038/nrc.2016.140)

Callahan SJ, Tepan S, Zhang YM, Lindsay H, Burger A, Campbell NR, Kim IS, Hollmann TJ, Studer L, Mosimann C, et al. 2018 Cancer modeling by transgene electroporation in adult zebrafish (TEAZ). Disease Models and Mechanisms 11 dmm034561. (https://doi. org/10.1242/dmm.034561)

Chanson P \& Salenave S 2008 Acromegaly. Orphanet Journal of Rare Diseases 3 17. (https://doi.org/10.1186/1750-1172-3-17)

Chen JY \& Chiou MJ 2010 Molecular cloning and functional analysis of the zebrafish luteinizing hormone beta subunit $(\mathrm{LH}<$ beta $>$ ) promoter. Fish Physiology and Biochemistry 36 1253-1262. (https://doi. org/10.1007/s10695-010-9405-8)

Cirello V, Gaudenzi G, Grassi ES, Colombo C, Vicentini L, Ferrero S, Persani L, Vitale G \& Fugazzola L 2018 Tumor and normal thyroid spheroids: from tissues to zebrafish. Minerva Endocrinologica 43 1-10. (https://doi.org/10.23736/S0391-1977.17.02610-4)

De Angelis C, Cortegoso Valdivia P, Venezia L, Bruno M \& Pellicano R 2018 Diagnosis and management of Zollinger-Ellison syndrome in 2018. Minerva Endocrinologica 43 212-220. (https://doi.org/10.23736/ S0391-1977.17.02745-6)

De Jong JL \& Zon LI 2005 Use of the zebrafish system to study primitive and definitive hematopoiesis. Annual Review of Genetics 39 481-501. (https://doi.org/10.1146/annurev.genet.39.073003.095931)

Eaton JL, Holmqvist B \& Glasgow E 2008 Ontogeny of vasotocinexpressing cells in zebrafish: selective requirement for the transcriptional regulators orthopedia and single-minded 1 in the preoptic area. Developmental Dynamics 237 995-1005. (https://doi. org/10.1002/dvdy.21503)

Elbialy A, Asakawa S, Watabe S \& Kinoshita S 2018 A zebrafish acromegaly model elevates DNA damage and impairs DNA repair pathways. Biology 7 E47. (https://doi.org/10.3390/biology7040047)

Ellett F, Pase L, Hayman JW, Andrianopoulos A \& Lieschke GJ 2011 mpeg1 promoter transgenes direct macrophage-lineage expression in zebrafish. Blood 117 e49-e56. (https://doi.org/10.1182/blood-2010-10-314120)

Eto K, Mazilu-Brown JK, Henderson-Maclennan N, Dipple KM \& Mccabe ER 2014 Development of catecholamine and cortisol stress responses in zebrafish. Molecular Genetics and Metabolism Reports $\mathbf{1}$ 373-377. (https://doi.org/10.1016/j.ymgmr.2014.08.003)

Finckbeiner S, Ko PJ, Carrington B, Sood R, Gross K, Dolnick B, Sufrin J \& Liu P 2011 Transient knockdown and overexpression reveal a developmental role for the zebrafish enosf $1 \mathrm{~b}$ gene. Cell and Bioscience 1 32. (https://doi.org/10.1186/2045-3701-1-32)
Fior R, Povoa V, Mendes RV, Carvalho T, Gomes A, Figueiredo N \& Ferreira MG 2017 Single-cell functional and chemosensitive profiling of combinatorial colorectal therapy in zebrafish xenografts. PNAS 114 E8234-E8243. (https://doi.org/10.1073/pnas.1618389114)

Fuentes-Fayos AC, Garcia-Martinez A, Herrera-Martinez AD, JimenezVacas JM, Vazquez-Borrego MC, Castano JP, Pico A, Gahete MD \& Luque RM 2019 Molecular determinants of the response to medical treatment of growth hormone secreting pituitary neuroendocrine tumors. Minerva Endocrinologica 44 109-128. (https://doi. org/10.23736/S0391-1977.19.02970-5)

Gaudenzi G, Albertelli M, Dicitore A, Wurth R, Gatto F, Barbieri F, Cotelli F, Florio T, Ferone D, Persani L, et al. 2017 Patient-derived xenograft in zebrafish embryos: a new platform for translational research in neuroendocrine tumors. Endocrine 57 214-219. (https:// doi.org/10.1007/s12020-016-1048-9)

Gaudenzi G, Dicitore A, Carra S, Saronni D, Pozza C, Giannetta E, Persani L \& Vitale G 2019 Management of endocrine disease: precision medicine in neuroendocrine neoplasms: an update on current management and future perspectives. European Journal of Endocrinology 181 R1-R10. (https://doi.org/10.1530/EJE-19-0021)

Gonzalez-Nunez V, Gonzalez-Sarmiento R \& Rodriguez RE 2003 Identification of two proopiomelanocortin genes in zebrafish (Danio rerio). Brain Research: Molecular Brain Research 120 1-8. (https://doi. org/10.1016/j.molbrainres.2003.09.012)

Grosse A, Perner B, Naumann U \& Englert C 2019 Zebrafish Wtx is a negative regulator of Wnt signaling but is dispensable for embryonic development and organ homeostasis. Developmental Dynamics $\mathbf{2 4 8}$ 866-881. (https://doi.org/10.1002/dvdy.84)

Hall C, Flores MV, Storm T, Crosier K \& Crosier P 2007 The zebrafish lysozyme $\mathrm{C}$ promoter drives myeloid-specific expression in transgenic fish. BMC Developmental Biology 7 42. (https://doi. org/10.1186/1471-213X-7-42)

Hason M \& Bartunek P 2019 Zebrafish models of cancer-new insights on modeling human cancer in a non-mammalian vertebrate. Genes $\mathbf{1 0}$ E935. (https://doi.org/10.3390/genes10110935)

Heanue TA, Boesmans W, Bell DM, Kawakami K, Vanden Berghe P \& Pachnis V 2016 A novel zebrafish ret heterozygous model of Hirschsprung disease identifies a functional role for mapk10 as a modifier of enteric nervous system phenotype severity. PLoS Genetics 12 e1006439. (https://doi.org/10.1371/journal.pgen.1006439)

Herzog W, Zeng X, Lele Z, Sonntag C, Ting JW, Chang CY \& Hammerschmidt M 2003 Adenohypophysis formation in the zebrafish and its dependence on sonic hedgehog. Developmental Biology 254 36-49. (https://doi.org/10.1016/s0012-1606(02)00124-0)

Hesselson D, Anderson RM, Beinat M \& Stainier DY 2009 Distinct populations of quiescent and proliferative pancreatic beta-cells identified by HOTcre mediated labeling. PNAS 106 14896-14901. (https://doi.org/10.1073/pnas.0906348106)

Igreja S, Chahal HS, King P, Bolger GB, Srirangalingam U, Guasti L, Chapple JP, Trivellin G, Gueorguiev M, Guegan K, et al. 2010 Characterization of aryl hydrocarbon receptor interacting protein (AIP) mutations in familial isolated pituitary adenoma families. Human Mutation 31 950-960. (https://doi.org/10.1002/humu.21292)

Keightley MC, Wang CH, Pazhakh V \& Lieschke GJ 2014 Delineating the roles of neutrophils and macrophages in zebrafish regeneration models. International Journal of Biochemistry and Cell Biology $\mathbf{5 6}$ 92-106. (https://doi.org/10.1016/j.biocel.2014.07.010)

Ki DH, He S, Rodig S \& Look AT 2017 Overexpression of PDGFRA cooperates with loss of NF1 and p53 to accelerate the molecular pathogenesis of malignant peripheral nerve sheath tumors. Oncogene 36 1058-1068. (https://doi.org/10.1038/onc.2016.269)

Kim SH, Speirs CK, Solnica-Krezel L \& Ess KC 2011 Zebrafish model of tuberous sclerosis complex reveals cell-autonomous and non-cellautonomous functions of mutant tuberin. Disease Models and Mechanisms 4 255-267. (https://doi.org/10.1242/dmm.005587) https://erc.bioscientifica.com

https://doi.org/10.1530/ERC-19-0437 (c) 2020 Society for Endocrinology Published by Bioscientifica Ltd. Printed in Great Britain 
Kim SH, Kowalski ML, Carson RP, Bridges LR \& Ess KC 2013 Heterozygous inactivation of tsc2 enhances tumorigenesis in p53 mutant zebrafish. Disease Models and Mechanisms 6 925-933. (https:// doi.org/10.1242/dmm.011494)

Kim HT, Lee MS, Jeong YM, Ro H, Kim DI, Shin YH, Kim JE, Hwang KS, Choi JH, Bahn M, et al. 2017 Ottogi inhibits Wnt/beta-catenin signaling by regulating cell membrane trafficking of Frizzled8. Scientific Reports 7 13278. (https://doi.org/10.1038/s41598-017-13429-6)

Koga Y \& Ochiai A 2019 Systematic review of patient-derived xenograft models for preclinical studies of anti-cancer drugs in solid tumors. Cells 8 E418. (https://doi.org/10.3390/cells8050418)

Konantz M, Balci TB, Hartwig UF, Dellaire G, Andre MC, Berman JN \& Lengerke C 2012 Zebrafish xenografts as a tool for in vivo studies on human cancer. Annals of the New York Academy of Sciences 1266 124-137. (https://doi.org/10.1111/j.1749-6632.2012.06575.x)

Krishnan J \& Rohner N 2019 Sweet fish: fish models for the study of hyperglycemia and diabetes. Journal of Diabetes 11 193-203. (https:// doi.org/10.1111/1753-0407.12860)

Langenau DM, Ferrando AA, Traver D, Kutok JL, Hezel JP, Kanki JP, Zon LI, Look AT \& Trede NS 2004 In vivo tracking of T cell development, ablation, and engraftment in transgenic zebrafish. PNAS 101 7369-7374. (https://doi.org/10.1073/pnas.0402248101)

Lawson ND \& Weinstein BM 2002 In vivo imaging of embryonic vascular development using transgenic zebrafish. Developmental Biology 248 307-318. (https://doi.org/10.1006/dbio.2002.0711)

Lin $\mathrm{CH}$, Su CH \& Hwang PP 2014 Calcium-sensing receptor mediates $\mathrm{Ca}(2+)$ homeostasis by modulating expression of PTH and stanniocalcin. Endocrinology 155 56-67. (https://doi.org/10.1210/ en.2013-1608)

Liu NA, Huang H, Yang Z, Herzog W, Hammerschmidt M, Lin S \& Melmed S 2003 Pituitary corticotroph ontogeny and regulation in transgenic zebrafish. Molecular Endocrinology 17 959-966. (https:// doi.org/10.1210/me.2002-0392)

Liu NA, Jiang H, Ben-Shlomo A, Wawrowsky K, Fan XM, Lin S \& Melmed S 2011 Targeting zebrafish and murine pituitary corticotroph tumors with a cyclin-dependent kinase (CDK) inhibitor. PNAS 108 8414-8419. (https://doi.org/10.1073/pnas.1018091108)

Liu J, Zhou Y, Qi X, Chen J, Chen W, Qiu G, Wu Z \& Wu N 2017 CRISPR/Cas9 in zebrafish: an efficient combination for human genetic diseases modeling. Human Genetics 136 1-12. (https://doi. org/10.1007/s00439-016-1739-6)

Lohr H \& Hammerschmidt M 2011 Zebrafish in endocrine systems: recent advances and implications for human disease. Annual Review of Physiology 73 183-211. (https://doi.org/10.1146/annurevphysiol-012110-142320)

Lopez M, Nica G, Motte P, Martial JA, Hammerschmidt M \& Muller M 2006 Expression of the somatolactin beta gene during zebrafish embryonic development. Gene Expression Patterns 6 156-161. (https://doi.org/10.1016/j.modgep.2005.06.010)

Manfredi GI, Dicitore A, Gaudenzi G, Caraglia M, Persani L \& Vitale G 2015 PI3K/Akt/mTOR signaling in medullary thyroid cancer: a promising molecular target for cancer therapy. Endocrine 48 363-370. (https://doi.org/10.1007/s12020-014-0380-1)

Mizgireuv IV \& Revskoy SY 2006 Transplantable tumor lines generated in clonal zebrafish. Cancer Research 66 3120-3125. (https://doi. org/10.1158/0008-5472.CAN-05-3800)

Mizgirev IV, Safina DR, Demidyuk IV \& Kostrov SV 2018 Organism-level tumor models in zebrafish Danio rerio. Acta Naturae 10 24-29. (https://doi.org/10.32607/20758251-2018-10-2-24-29)

Moore JC, Tang Q, Yordan NT, Moore FE, Garcia EG, Lobbardi R, Ramakrishnan A, Marvin DL, Anselmo A, Sadreyev RI, et al. 2016 Single-cell imaging of normal and malignant cell engraftment into optically clear prkdc-null SCID zebrafish. Journal of Experimental Medicine 213 2575-2589. (https://doi.org/10.1084/jem.20160378)

Morton CL \& Houghton PJ 2007 Establishment of human tumor xenografts in immunodeficient mice. Nature Protocols 2 247-250. (https://doi.org/10.1038/nprot.2007.25)

(c) 2020 Society for Endocrinology Published by Bioscientifica Ltd. Printed in Great Britain
Nasevicius A \& Ekker SC 2000 Effective targeted gene 'knockdown' in zebrafish. Nature Genetics 26 216-220. (https://doi. org/10.1038/79951)

Nesan D \& Vijayan MM 2013 Role of glucocorticoid in developmental programming: evidence from zebrafish. General and Comparative Endocrinology 181 35-44. (https://doi.org/10.1016/j. ygcen.2012.10.006)

Nguyen-Chi M, Laplace-Builhe B, Travnickova J, Luz-Crawford P, Tejedor G, Phan QT, Duroux-Richard I, Levraud JP, Kissa K, Lutfalla $G$, et al. 2015 Identification of polarized macrophage subsets in zebrafish. eLife 4 e07288. (https://doi.org/10.7554/eLife.07288)

Njagi J, Ball M, Best M, Wallace KN \& Andreescu S 2010 Electrochemical quantification of serotonin in the live embryonic zebrafish intestine. Analytical Chemistry 82 1822-1830. (https://doi.org/10.1021/ac902465v)

Okabe M \& Graham A 2004 The origin of the parathyroid gland. PNAS 101 17716-17719. (https://doi.org/10.1073/pnas.0406116101)

Osmani N \& Goetz JG 2019 Multiscale imaging of metastasis in zebrafish. Trends in Cancer 5 766-778. (https://doi.org/10.1016/j. trecan.2019.10.003)

Paul CD, Devine A, Bishop K, Xu Q, Wulftange WJ, Burr H, Daly KM, Lewis C, Green DS, Staunton JR, et al. 2019 Human macrophages survive and adopt activated genotypes in living zebrafish. Scientific Reports 9 1759. (https://doi.org/10.1038/s41598-018-38186-y)

Peverelli E, Giardino E, Treppiedi D, Meregalli M, Belicchi M, Vaira V, Corbetta S, Verdelli C, Verrua E, Serban AL, et al. 2017 Dopamine receptor type 2 (DRD2) and somatostatin receptor type 2 (SSTR2) agonists are effective in inhibiting proliferation of progenitor/stemlike cells isolated from nonfunctioning pituitary tumors. International Journal of Cancer 140 1870-1880. (https://doi.org/10.1002/ijc.30613)

Pogoda HM \& Hammerschmidt M 2007 Molecular genetics of pituitary development in zebrafish. Seminars in Cell and Developmental Biology 18 543-558. (https://doi.org/10.1016/j.semcdb.2007.04.004)

Postlethwait JH, Woods IG, Ngo-Hazelett P, Yan YL, Kelly PD, Chu F, Huang H, Hill-Force A \& Talbot WS 2000 Zebrafish comparative genomics and the origins of vertebrate chromosomes. Genome Research 10 1890-1902. (https://doi.org/10.1101/gr.164800)

Renshaw SA, Loynes CA, Trushell DM, Elworthy S, Ingham PW \& Whyte MK 2006 A transgenic zebrafish model of neutrophilic inflammation. Blood 108 3976-3978. (https://doi.org/10.1182/blood2006-05-024075)

Richard S, Gardie B, Couve S \& Gad S 2013 Von Hippel-Lindau: how a rare disease illuminates cancer biology. Seminars in Cancer Biology 23 26-37. (https://doi.org/10.1016/j.semcancer.2012.05.005)

Rindi G \& Wiedenmann B 2011 Neuroendocrine neoplasms of the gut and pancreas: new insights. Nature Reviews: Endocrinology 8 54-64. (https://doi.org/10.1038/nrendo.2011.120)

Rios Y, Melmed S, Lin S \& Liu NA 2011 Zebrafish usp39 mutation leads to rb1 mRNA splicing defect and pituitary lineage expansion. PLoS Genetics 7 e1001271. (https://doi.org/10.1371/journal.pgen.1001271)

Santoriello C \& Zon LI 2012 Hooked! Modeling human disease in zebrafish. Journal of Clinical Investigation 122 2337-2343. (https://doi. org/10.1172/JCI60434)

Scheldeman C, Mills JD, Siekierska A, Serra I, Copmans D, Iyer AM, Whalley BJ, Maes J, Jansen AC, Lagae L, et al. 2017 mTOR-related neuropathology in mutant tsc 2 zebrafish: phenotypic, transcriptomic and pharmacological analysis. Neurobiology of Disease 108 225-237. (https://doi.org/10.1016/j.nbd.2017.09.004)

Serra I, Scheldeman C, Bazelot M, Whalley BJ, Dallas ML, De Witte PAM \& Williams CM 2019 Cannabidiol modulates phosphorylated rpS6 signalling in a zebrafish model of tuberous sclerosis complex. Behavioural Brain Research 363 135-144. (https://doi.org/10.1016/j. bbr.2019.01.040)

Shin J, Padmanabhan A, De Groh ED, Lee JS, Haidar S, Dahlberg S, Guo F, He S, Wolman MA, Granato M, et al. 2012 Zebrafish neurofibromatosis type 1 genes have redundant functions in tumorigenesis and embryonic development. Disease Models and Mechanisms 5 881-894. (https://doi.org/10.1242/dmm.009779) 
Shive HR 2013 Zebrafish models for human cancer. Veterinary Pathology 50 468-482. (https://doi.org/10.1177/0300985812467471)

Smith AC, Raimondi AR, Salthouse CD, Ignatius MS, Blackburn JS, Mizgirev IV, Storer NY, De Jong JL, Chen AT, Zhou Y, et al. 2010 Highthroughput cell transplantation establishes that tumor-initiating cells are abundant in zebrafish T-cell acute lymphoblastic leukemia. Blood 115 3296-3303. (https://doi.org/10.1182/blood-2009-10-246488)

So WK, Kwok HF \& Ge W 2005 Zebrafish gonadotropins and their receptors: II. Cloning and characterization of zebrafish folliclestimulating hormone and luteinizing hormone subunits - their spatial-temporal expression patterns and receptor specificity. Biology of Reproduction 72 1382-1396. (https://doi.org/10.1095/ biolreprod.104.038216)

Stern HM \& Zon LI 2003 Cancer genetics and drug discovery in the zebrafish. Nature Reviews: Cancer 3 533-539. (https://doi.org/10.1038/ nrc1126)

Stojanovic MA, Aflorei ED, McGonnel I \& Korbonits M 2016 AIP inactivation leads to pituitary enlargement in the zebrafish embryo model. Presented at the 18th European Congress of Endocrinology, Munich, Germany. Endocrine Abstracts 41 EP854. (https://doi. org/10.1530/endoabs.41.EP854)

Stoletov K \& Klemke R 2008 Catch of the day: zebrafish as a human cancer model. Oncogene 27 4509-4520. (https://doi.org/10.1038/onc.2008.95)

Strizzi L, Hardy KM, Seftor EA, Costa FF, Kirschmann DA, Seftor RE, Postovit LM \& Hendrix MJ 2009 Development and cancer: at the crossroads of Nodal and Notch signaling. Cancer Research 69 7131-7134. (https://doi.org/10.1158/0008-5472.CAN-09-1199)

Tang Q, Abdelfattah NS, Blackburn JS, Moore JC, Martinez SA, Moore FE, Lobbardi R, Tenente IM, Ignatius MS, Berman JN, et al. 2014 Optimized cell transplantation using adult rag2 mutant zebrafish. Nature Methods 11 821-824. (https://doi.org/10.1038/nmeth.3031)

Tiso N, Moro E \& Argenton F 2009 Zebrafish pancreas development. Molecular and Cellular Endocrinology 312 24-30. (https://doi. org/10.1016/j.mce.2009.04.018)

Toro S, Wegner J, Muller M, Westerfield M \& Varga ZM 2009 Identification of differentially expressed genes in the zebrafish hypothalamic-pituitary axis. Gene Expression Patterns 9 200-208. (https://doi.org/10.1016/j.gep.2008.12.007)

Traver D, Winzeler A, Stern HM, Mayhall EA, Langenau DM, Kutok JL, Look AT \& Zon LI 2004 Effects of lethal irradiation in zebrafish and rescue by hematopoietic cell transplantation. Blood 104 1298-1305. (https://doi.org/10.1182/blood-2004-01-0100)

Unger JL \& Glasgow E 2003 Expression of isotocin-neurophysin mRNA in developing zebrafish. Gene Expression Patterns 3 105-108. (https:// doi.org/10.1016/s1567-133x(02)00064-9)

Uri I \& Grozinsky-Glasberg S 2018 Current treatment strategies for patients with advanced gastroenteropancreatic neuroendocrine tumors (GEP-NETs). Clinical Diabetes and Endocrinology 4 16. (https:// doi.org/10.1186/s40842-018-0066-3)

Van Rooijen E, Voest EE, Logister I, Bussmann J, Korving J, Van Eeden FJ, Giles RH \& Schulte-Merker S 2010 Von Hippel-Lindau tumor suppressor mutants faithfully model pathological hypoxia-driven angiogenesis and vascular retinopathies in zebrafish. Disease Models and Mechanisms 3 343-353. (https://doi.org/10.1242/dmm.004036)

Van Rooijen E, Santhakumar K, Logister I, Voest E, Schulte-Merker S, Giles R \& Van Eeden F 2011 A zebrafish model for VHL and hypoxia signaling. Methods in Cell Biology 105 163-190. (https://doi. org/10.1016/B978-0-12-381320-6.00007-2)

Van Rooijen E, Van De Hoek G, Logister I, Ajzenberg H, Knoers NVAM, Van Eeden F, Voest EE, Schulte-Merker S \& Giles RH 2018 The von
Hippel-Lindau gene is required to maintain renal proximal tubule and glomerulus integrity in zebrafish larvae. Nephron 138 310-323. (https://doi.org/10.1159/000484096)

Vitale G, Caraglia M, Ciccarelli A, Lupoli G, Abbruzzese A, Tagliaferri P \& Lupoli G 2001 Current approaches and perspectives in the therapy of medullary thyroid carcinoma. Cancer 91 1797-1808. (https://doi. org/10.1002/1097-0142(20010501)91:9<1797::aid-cncr1199>3.0.co;2-p)

Vitale G, Gaudenzi G, Dicitore A, Cotelli F, Ferone D \& Persani L 2014 Zebrafish as an innovative model for neuroendocrine tumors. EndocrineRelated Cancer 21 R67-R83. (https://doi.org/10.1530/ERC-13-0388)

Vitale G, Gaudenzi G, Circelli L, Manzoni MF, Bassi A, Fioritti N, Faggiano A, Colao A \& NIKE Group 2017 Animal models of medullary thyroid cancer: state of the art and view to the future. Endocrine-Related Cancer 24 R1-R12. (https://doi.org/10.1530/ERC-160399)

Wang J, Cao Z, Zhang XM, Nakamura M, Sun M, Hartman J, Harris RA, Sun Y \& Cao Y 2015 Novel mechanism of macrophage-mediated metastasis revealed in a zebrafish model of tumor development. Cancer Research 75 306-315. (https://doi.org/10.1158/0008-5472. CAN-14-2819)

Wang M, Zhao J, Zhang L, Wei F, Lian Y, Wu Y, Gong Z, Zhang S, Zhou J, Cao K, et al. 2017 Role of tumor microenvironment in tumorigenesis. Journal of Cancer 8 761-773. (https://doi.org/10.7150/ jca.17648)

Ward R, Ali Z, Slater K, Reynolds AL, Jensen LD \& Kennedy BN 2019 Pharmacological restoration of visual function in a zebrafish model of Von-Hippel Lindau disease. Developments in Biologicals $\mathbf{4 5 7}$ 226-234. (https://doi.org/10.1016/j.ydbio.2019.02.008)

White RM, Sessa A, Burke C, Bowman T, Leblanc J, Ceol C, Bourque C, Dovey M, Goessling W, Burns CE, et al. 2008 Transparent adult zebrafish as a tool for in vivo transplantation analysis. Cell Stem Cell 2 183-189. (https://doi.org/10.1016/j.stem.2007.11.002)

Wurth R, Barbieri F, Pattarozzi A, Gaudenzi G, Gatto F, Fiaschi P, Ravetti JL, Zona G, Daga A, Persani L, et al. 2017 Phenotypical and pharmacological characterization of stem-like cells in human pituitary adenomas. Molecular Neurobiology 54 4879-4895. (https:// doi.org/10.1007/s12035-016-0025-x)

Yan C, Brunson DC, Tang Q, Do D, Iftimia NA, Moore JC, Hayes MN, Welker AM, Garcia EG, Dubash TD, et al. 2019 Visualizing engrafted human cancer and therapy responses in immunodeficient zebrafish. Cell 177 1903.e14-1914.e14. (https://doi.org/10.1016/j. cell.2019.04.004)

Yang HW, Kutok JL, Lee NH, Piao HY, Fletcher CD, Kanki JP \& Look AT 2004 Targeted expression of human MYCN selectively causes pancreatic neuroendocrine tumors in transgenic zebrafish. Cancer Research 64 7256-7262. (https://doi.org/10.1158/0008-5472.CAN-04-0931)

Zhan T, Rindtorff N \& Boutros M 2017 Wnt signaling in cancer. Oncogene 36 1461-1473. (https://doi.org/10.1038/onc.2016.304)

Zhao S, Huang J \& Ye J 2015 A fresh look at zebrafish from the perspective of cancer research. Journal of Experimental and Clinical Cancer Research 34 80. (https://doi.org/10.1186/s13046-015-0196-8)

Zhu Y, Stiller JW, Shaner MP, Baldini A, Scemama JL \& Capehart AA 2004 Cloning of somatolactin alpha and beta cDNAs in zebrafish and phylogenetic analysis of two distinct somatolactin subtypes in fish. Journal of Endocrinology 182 509-518. (https://doi.org/10.1677/ joe.0.1820509)

Zhu S, Lee JS, Guo F, Shin J, Perez-Atayde AR, Kutok JL, Rodig SJ, Neuberg DS, Helman D, Feng H, et al. 2012 Activated ALK collaborates with MYCN in neuroblastoma pathogenesis. Cancer Cell 21 362-373. (https://doi.org/10.1016/j.ccr.2012.02.010) https://erc.bioscientifica.com https://doi.org/10.1530/ERC-19-0437 (c) 2020 Society for Endocrinology Published by Bioscientifica Ltd. Printed in Great Britain
Received in final form 1 April 2020

Accepted 3 April 2020

Accepted Manuscript published online 6 April 2020 